This is the author's version of a work that was accepted for publication in Ceramics International. Changes resulting from the publishing process, such as peer review, editing, corrections, structural formatting and other quality control mechanisms may not be reflected in this document. Changes may have been made to this work since it was submitted for publication. A definitive version was subsequently published in Ceramics International, Volume 40, Issue 5, 2013, Pages 7067-7072.

http://doi.org/10.1016/j.ceramint.2013.12.038 


\title{
Synthesis and Characterisation of Gel-Derived Mullite Precursors from Rice Husk Silica
}

\author{
Simon Sembiring ${ }^{1}$, Wasinton Simanjuntak ${ }^{2}$, Posman Manurung ${ }^{1}$, Dwi Asmi ${ }^{1}$, I.M. Low ${ }^{3 *}$ \\ ${ }^{1}$ Department of Physics, Faculty of Mathematics and Natural Sciences, University of Lampung, \\ Bandar Lampung, 35145, Indonesia \\ ${ }^{2}$ Department of Chemistry, Faculty of Mathematics and Natural Science, University of Lampung \\ Bandar Lampung, 35145, Indonesia \\ ${ }^{3}$ Department of Applied Physics, Curtin University, GPO Box U1987, Perth WA Australia 6845
}

*Corresponding author: j.low@curtin.edu.au (I.M. Low)

The sol-gel synthesis and characterization of mullite precursor derived from rice husk silica and aluminum nitrate hydrate $\left[\left(\mathrm{Al}\left(\mathrm{NO}_{3}\right)_{3} \cdot 9 \mathrm{H}_{2} \mathrm{O}\right]\right.$ has been investigated. The samples were characterized using Fourier transform infrared (FTIR) spectroscopy, x-ray diffraction (XRD) coupled with Rietveld analysis, and scanning electron microscopy (SEM). FTIR results showed the presence of Si-O-Si, Al-O-Al, and Si-O-Al functional groups, which were associated with mullite, corundum, quartz, and cristobalite, as verified by XRD analysis. It is concluded that mullite formation started at $1150{ }^{\circ} \mathrm{C}$, and its abundance increased rapidly with an increase in temperature from $1150-1350{ }^{\circ} \mathrm{C}$, resulting in increased phase content from 30.9 to $67.7 \mathrm{wt} \%$. Although mullite was formed at a low temperature, the complete reaction between corundum and silica to form mullite was not achieved. This finding demonstrated that rice husk silica is a potential alternative raw material for the production of mullite ceramic.

Keywords:A: ceramics; B: Sol-gel growth; C: Electron microscopy; C: Fourier transform infrared spectroscopy (FTIR); C: X-ray scattering; D: phase transitions 


\section{Introduction}

Mullite $\left(3 \mathrm{Al}_{2} \mathrm{O}_{3} \cdot 2 \mathrm{SiO}_{2}\right)$ is a refractory aluminosilicate material that belongs to the $\mathrm{Al}_{2} \mathrm{O}_{3}-\mathrm{SiO}_{2}$ system. This ceramic is an interesting material because of its various attractive properties which include high thermal stability, low thermal expansion and conductivity, high melting point and chemical stability, and high thermal shock resistance [1-5]. For these reasons, mullite has been widely used as an advanced structural or functional ceramic in various applications such as components in reinforced composites [6], microelectronic packaging and substrates [7], and optical component of infrared windows [8].

In general it is well established that the method of synthesis and raw material play an important role in determining the mullitization temperature and the homogeneity of the product. The method used for the synthesis of mullite is an important factor because it determines the degree of mixing of aluminum and silicon in the precursor, which in turn influences the mullitization temperature. Many methods to synthesize mullite have been developed, however, the sol-gel approach is acknowledged as the most attractive because it enables good mixing to promote uniformity of the starting materials, resulting in very homogeneous distribution of elements at the atomic level to produce mono-phasic gels [9]. As a result, the formation of mullite from gels could be achieved at temperatures in the range of 1000 and $1250^{\circ} \mathrm{C}$ [10-12], which are lower than those required in the solid state (i.e., powder mixture) method, in which the temperatures range from 1240 to $1350^{\circ} \mathrm{C}$ [13]. In addition to the synthesis method, types of precursors have been reported to strongly influence the mullitization temperature. For example, crystalline mullite can be produced at $\sim 1000^{\circ} \mathrm{C}$ from aluminosiloxanes [14], and at $\sim 1350^{\circ} \mathrm{C}$ using kyanite and alumina powder [15]. Production of mullite from alumina and silica sols indicated that amorphous mullite forms at around $600{ }^{\circ} \mathrm{C}$ and can be sintered into dense mullite at $1600{ }^{\circ} \mathrm{C}$ [16]. Previous study by Cividanes et.al., (2010) [17] revealed that mullitization lies at the interface between liquid phase and crystalline corundum $\left(\alpha-\mathrm{Al}_{2} \mathrm{O}_{3}\right)$ and the subsequent growth of the mullite phase was generated by $\mathrm{Al}^{3+}$ and $\mathrm{Si}^{4+}$ interdiffusion. In another 
study [18], it was found that by atomic scale mixing of metal salts and metal alkoxides, mullite, spinel and silica segregation can occur simultaneously at $980{ }^{\circ} \mathrm{C}$. In another study using kaolinite and alumina [19], it was reported that both mullite and spinel were detected in the sample sintered at $980{ }^{\circ} \mathrm{C}$, while Chen et al., (2004) [20] reported the formation of spinel, alumina and silica at 980 ${ }^{\circ} \mathrm{C}$, followed by mullite formation at $1100{ }^{\circ} \mathrm{C}$. Fully densified mullite was obtained at $1300{ }^{\circ} \mathrm{C}$ using raw wastes containing high silica (slate rock) and aluminum hydroxide (aluminum sludge) [21].

Rice husk is currently being considered as an important and competitive resource for the production of high purity and amorphous silica [22], which is essential for the synthesis of various materials such as iron/silica catalyst [23], cordierite [24,25], silicon carbide [26], magnesiumaluminum-silica [27], lithium-aluminum-silica [28], borosilicate [29], and silica aerogel [30]. Utilization of rice husk is attractive because of the possibility of removing impurities to produce active silica with high specific surface area at relatively low cost. In addition, active silica from rice husk is naturally amorphous but can be transformed into crystalline phases, such as cristobalite and tridymite, by thermal treatment at between $700-1400{ }^{\circ} \mathrm{C}$ [31]. To take advantage of the availability and suitable properties of rice husk silica, the present study utilized this silica as a raw material for the synthesis of mullite precursor using the sol-gel technique. The main purpose of this study was to evaluate development of mullite as a function of sintering temperature, based on the changes in the functionality, structure, and microstructure of the samples. The functionality change as a function of heat treatment was investigated using FTIR spectroscopy, the structure was characterized by XRD coupled with Rietveld analysis, and the microstructure was examined using SEM. Rietveld refinement of the XRD data was carried out to ascertain the quantitative phase compositions of the samples.

\section{Experimental Methods}

\subsection{Materials}


Raw materials used for the synthesis of mullite were rice husk silica and [( $\left.\mathrm{Al}\left(\mathrm{NO}_{3}\right)_{3} \cdot 9 \mathrm{H}_{2} \mathrm{O}\right]$ (Merck, Germany) as a source of alumina. $\mathrm{KOH}$ and $\mathrm{HCl}$ used were reagent grade obtained from Merck.

\subsection{Procedure}

Rice husk silica was obtained using an alkali extraction method previously reported [29]. In this procedure, $50 \mathrm{~g}$ dried husk was mixed with $500 \mathrm{ml}$ of $5 \% \mathrm{KOH}$ solution in a beaker glass. The mixture was boiled for 30 minutes, and then allowed to cool to room temperature and left for 24 hours. The mixture was filtered through a Millipore filter to separate the filtrate which contained silica (silica sol). To obtain solid silica, the sol was acidified by additing $5 \% \mathrm{HCl}$ solution until the sol was converted into gel. The gel was aged for three days, and then rinsed repeatedly with deionised water to remove the excess acid. The gel was then oven dried at $110{ }^{\circ} \mathrm{C}$ for eight hours and then ground into powder. A specified amount of silica powder was redissolved in $5 \% \mathrm{KOH}$ solution to obtain a silica sol for the synthesis of mullite. Alumina sol was prepared by dissolving $44 \mathrm{~g}$ of $\mathrm{Al}\left(\mathrm{NO}_{3}\right)_{3} \cdot 9 \mathrm{H}_{2} \mathrm{O}$ in $100 \mathrm{ml}$ ethanol under magnetic stirring for 1 hour and then kept in a tightly covered conical flask. The preparation of mullite precursor was carried out by slow addition of appropriate volume of $\mathrm{Al}\left(\mathrm{NO}_{3}\right)_{3} \cdot 9 \mathrm{H}_{2} \mathrm{O}$ solution into the specified volume of silica sol to give the mol ratio of alumina to silica of 3:2 [32]. The mixture was then magnetically stirred, during which $\mathrm{HCl}$ solution was added slowly to produce a gel. The gel was then aged for three days, rinsed repeatedly with deionised water to remove excess acid and alkali, and then oven dried at $110{ }^{\circ} \mathrm{C}$ for 12 hours. Dry gels were heat-treated in a ventilated furnace at the peak temperatures of 800, 950, 1050, 1150, 1250 , and $1350{ }^{\circ} \mathrm{C}$ with 6 hours dwell time at each peak temperature. The heating rate used was $5{ }^{\circ} \mathrm{C} / \mathrm{min}$.

\subsection{Characterisation}


A Perkin Elmer FTIR spectrometer was used for the investigation of functional groups of mullite. The sample was mixed with $\mathrm{KBr}$, and scanned in the spectral range of $4000-400 \mathrm{~cm}^{-1}$. XRD patterns were recorded to analyze mullite formation and the effect of sintering temperature on mullite abundance. The samples were examined using an automated Shimadzu XD-610 X-ray diffractometer at the Agency of Nuclear Energy National (BATAN), Serpong-Indonesia. The operating conditions used were $\mathrm{CuK}_{\alpha}$ radiation $(\lambda=0.15418 \AA)$, produced at $40 \mathrm{kV}$ and $30 \mathrm{~mA}$,

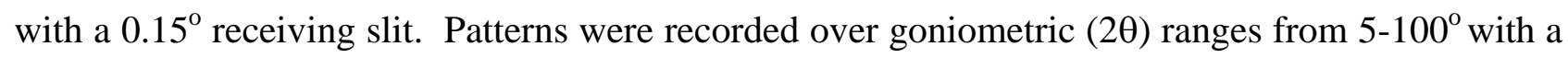
step size of 0.02 , counting time 1s/step, and using post-diffraction graphite monochromator with a NaI detector. The diffraction data were analyzed using the JADE software after subtracting background and stripping the $\mathrm{CuK}_{\alpha 2}$ pattern[33] and the refinements were performed using the Rietica program for Windows 95/98/NT version 1.70[34]. Microstructural examination on polished and thermally-etched samples was carried out using a Philips-XL scanning electron microscope.

\section{Results and Discussion}

\subsection{Characteristics of rice husk silica}

In our previous study [29], we described the functionality of rice husk silica as determined from the FTIR technique. Briefly, the FTIR spectrum is marked by the presence of several functional groups associated with silica, including $\mathrm{Si}-\mathrm{OH}, \mathrm{Si}-\mathrm{O}-\mathrm{Si}$, and O-Si-O groups. No absorption bands associated with the organic functional groups were detected, indicating that high purity rice husk silica could be obtained using alkali extraction followed by the sol-gel method. Other basic characteristics of rice husk silica we investigated previously [35] were phase structure using x-ray diffraction (XRD) and scanning electron microscopy (SEM). Reults of XRD indicated that the silica is essentially amorphous, which is in agreement with the work of others [22,31], and the results of SEM showed that the surface of silica is composed of agglomerated particles which 
are relatively uniform in size and distributed homogeneously on the surface. These basic characteristics of rice husk silica demonstrated that this bio-silica possesses a high potential to be utilized as raw material for production of mullite precursor and other silica based materials. This potential is the main reason for carrying out this study as an attempt to evaluate the feasibility of using this agriculture waste as an alternative raw material for mullite production.

\subsection{Characteristics of synthesized mullite precursor}

Fig. 1(a) shows the infrared spectrum of the original (non-sintered) sample and Fig. 1(b-g) present the spectra of samples subjected to heat treatment at different temperatures. For the non-sintered sample (Fig. 1a), the most obvious peak is located at $3476 \mathrm{~cm}^{-1}$, which is commonly assigned to the stretching vibration of $\mathrm{O}-\mathrm{H}$ bonds present in $\mathrm{Al}(\mathrm{OH})_{3}, \mathrm{Si}(\mathrm{OH})_{4}$, and trapped water. The contribution of water is confirmed by the absorption band at $1640 \mathrm{~cm}^{-1}$ [36], which is commonly assigned to the bending vibration of $\mathrm{H}-\mathrm{OH}$ bonds. Another strong band observed is located at 1388

$\mathrm{cm}^{-1}$, which is the characteristic stretching vibration of the entrapped nitrate ions of $\mathrm{Al}\left(\mathrm{NO}_{3}\right)_{3} \cdot 9 \mathrm{H}_{2} \mathrm{O}$ [23]. The wide and weak peak located at $1103 \mathrm{~cm}^{-1}$ is commonly assigned to the stretching vibration of Si-O-Si. The presence of absorption peaks at $1640 \mathrm{~cm}^{-1}$ and at $1103 \mathrm{~cm}^{-1}$ suggest that the sample is still dominated by $\mathrm{Si}(\mathrm{OH})_{4}$.

Fig. 1(b-g) indicate the significant effect of thermal treatment on the functionality of the samples. The most obvious change is the absence of peaks associated with nitrate ions, confirming the release of the nitrogenous gases during the heating process. In addition, the intensity of the band assigned to $\mathrm{O}-\mathrm{H}$ bonds decreased due to the evaporation of trapped water and the release of $\mathrm{OH}$ species through the decomposition of $\mathrm{Si}(\mathrm{OH})_{4}$ and $\mathrm{Al}(\mathrm{OH})_{3}$ molecules into oxides. As a consequence, the intensity of the absorption band at $\sim 468 \mathrm{~cm}^{-1}$, assigned to Si-O-Si vibration, increased and accompanied by the emergence of a new band at $\sim 723 \mathrm{~cm}^{-1}$ assigned to Al-O-Al. The increased intensity of Si-O-Si indicates that the $\mathrm{Si}(\mathrm{OH})_{4}$ has been converted to $\mathrm{SiO}_{2}$, which is 
in agreement with the decreased intensity of the peaks assigned to O-H bonds, while the emergence of peak attributed to $\mathrm{Al}-\mathrm{O}-\mathrm{Al}$ is an indication of the conversion of $\mathrm{Al}(\mathrm{OH})_{3}$ into aluminum oxides. The results for sintered samples also display a gradual disappearance of absorption peak at 3476 $\mathrm{cm}^{-1}$ up to the sintering temperature of $1050{ }^{\circ} \mathrm{C}$ and practically disappeared at $1150{ }^{\circ} \mathrm{C}$. This implies that decomposition of $\mathrm{Si}(\mathrm{OH})_{4}$ and $\mathrm{Al}(\mathrm{OH})_{3}$ with the release of $\mathrm{OH}$ species was achieved at $1150{ }^{\circ} \mathrm{C}$, which also suggests that complete transformation of $\mathrm{Si}(\mathrm{OH})_{4}$ and $\mathrm{Al}(\mathrm{OH})_{3}$ into oxides has been achieved at this temperature. The conversion of $\mathrm{Al}(\mathrm{OH})_{3}$ into an oxide is in agreement with stepwise strengthening of the band associated with $\mathrm{Al}-\mathrm{O}-\mathrm{Al}$ at $723 \mathrm{~cm}^{-1}$. Another important finding is the formation of mullite at $1150{ }^{\circ} \mathrm{C}$, which continues to develop at higher temperatures, as indicated by the emergence of absorption band at $834 \mathrm{~cm}^{-1}$, which is assigned to Si-O-Al linkages, and the band at $613 \mathrm{~cm}^{-1}$ which implies the existence of an $\mathrm{Al}_{2} \mathrm{O}_{3} \cdot \mathrm{SiO}_{2}$ structure [37]. In the spectrum of the sample sintered at $950{ }^{\circ} \mathrm{C}$, a small peak was observed at $\sim 2368 \mathrm{~cm}^{-1}$, which is commonly assigned to the vibration band of C-O [36], probably originated from atmospheric $\mathrm{CO}_{2}$ adsorbed by the sample during its preparation. As can be seen, in the sample treated at low temperature, the peak is not detected, while in the samples treated at higher temperature (up to1250 ${ }^{\circ} \mathrm{C}$ ) the presence of the peak is quite obvious, suggesting that at higher temperatures the $\mathrm{CO}_{2}$ has dissociated and is bound as CO. In the sample treated at even higher temperature (i.e. $1350{ }^{\circ} \mathrm{C}$ ), the peak has practically disappeared, suggesting that at this temperature, the bound CO was driven off from the sample.

The XRD patterns of samples heat-treated at 950, 1150, 1250 and $1350{ }^{\circ} \mathrm{C}$ were recorded, and the crystalline phases formed are shown in Fig. 2(a-d). The phases were identified using the search-match method [38], showing the presence of mullite (PDF-15-0776), cristobalite (PDF-391425), corundum (PDF-46-1212), and quartz (PDF-46-1045). The cristobalite and quartz are most likely formed as a result of rice husk silica crystallization during the thermal treatment, while the corundum originated from aluminum nitrate. For the sample sintered at $950{ }^{\circ} \mathrm{C}$ (Fig. 2a) the 
presence of crystallite cristobalite and quartz was clearly detected, together with mullite and corundum as minor phases. This suggests that at this temperature the formation of mullite has commenced. Increasing the sintering temperatures was found to lead to substantial differences between the samples. The sample sintered at temperature of $1150{ }^{\circ} \mathrm{C}$ (Fig. 2b) is marked by a decrease in the intensity of quartz and corundum, while the intensities of cristobalite and mullite increased quite significantly compared to those observed in the sample sintered at $950{ }^{\circ} \mathrm{C}$ (Fig. 2a). The temperature of mullite formation observed in this study is lower than those reported by others using TEOS [10], in which it was reported mullitization started at $1000{ }^{\circ} \mathrm{C}$ and the formation of mullite was evident at $1100{ }^{\circ} \mathrm{C}$. Such decrease in peak intensity of quartz and corundum may be attributed to their reaction to form mullite through inter-diffusion between quartz and corundum that took place, as has also been observed by others [39]. Further treatment of the sample at 1250 ${ }^{\circ} \mathrm{C}$ and $1350{ }^{\circ} \mathrm{C}$ was found to lead to gradual increased amounts of mullite and cristobalite, and gradual reduction of corundum and quartz, which suggest that higher temperatures have promoted the conversion of corundum and quartz into mullite and cristobalite (Fig. 2c-d).

In order to obtain quantitative phase compositions, the XRD results were further analyzed using the Rietveld method. In addition to quantitative data on the phases formed, an additional information gained from Rietveld analysis is the detection of potassium chlorate in the sample. The presence of potassium chlorate $\left(\mathrm{KClO}_{4}\right)$ as impurity in the samples investigated is most likely originated from the residual $\mathrm{KOH}$ used for the extraction of silica and the naturally contained potassium in rice husk [22], as well as the chemical contamination from $\mathrm{HCl}$ used to produce gel.

Table 1 summarizes the weight percentage (wt\%) of various phases formed in all samples at different sintering temperatures, and the refinement results are listed in Table 2. As shown in Table 1, the amount of mullite increased as the sintering temperature increased from 950 to $1150{ }^{\circ} \mathrm{C}$, suggesting that the amorphous phase crystallized at $1150{ }^{\circ} \mathrm{C}$ to produce more mullite. It is also found that higher sintering temperature led to a reduced amount of potassium chlorate, due to the 
decomposition of this compound to produce chlorine gas which was expelled from the sample. At sintering temperatures higher than $1150{ }^{\circ} \mathrm{C}$ it was observed that the amount of mullite increased as a function of sintering temperature. The increasing abundance of mullite at above $1150{ }^{\circ} \mathrm{C}$, coincided with a decrease in quartz and potassium chlorate. This result implies that more quartz reacted with corundum to form mullite, and at the same time more potassium chlorite had decomposed. The reaction between quartz and corundum is clearly indicated by the non-detection of quartz and corundum in the sample heat-treated at $1350{ }^{\circ} \mathrm{C}$. As indicated in Table 2, the results of refinement converged for all samples with satisfactory values of goodness of fit (GOF) as required by Rietveld analysis.

The SEM images of samples subjected to heat-treatment at different temperatures are shown in Fig. 3. These images show that at lower temperatures (Fig. 3a and b), particle agglomerations on the surface are quite evident and clusters of different shapes and sizes are produced. These agglomerated particles can be attributed to the reaction of source materials as indicated by the formation of several phases. The microstructure of the sample sintered at $950{ }^{\circ} \mathrm{C}$ does not show any major difference to that of the sample heat-treated at $1050^{\circ} \mathrm{C}$. Both samples are marked by initial coalescence of silica spheres which are still amorphous. This feature suggests that at $950{ }^{\circ} \mathrm{C}$, part of the amorphous siliceous phase has started to melt which allowed for particles rearrangement through viscous flow of $\mathrm{SiO}_{2}$, before the formation of mullite at $1150{ }^{\circ} \mathrm{C}$ as indicated by the XRD results (see Table 1). The significant effect of sintering temperature on the microstructures of samples can be observed from the SEM images shown in Fig. 3(c-e). As can be seen, the micrograph of the sample treated at $1150{ }^{\circ} \mathrm{C}$ (Fig. 3c) displays uniform surface with small grain sizes, suggesting that liquefied silica has covered the entire surface. Some of the liquefied silica reacted with corundum to form mullite as indicated by the existence of small spherical grains (most likely corundum and solid silica) and lumps (most likely mullite). Increasing the sintering 
temperature was found to enhance the formation of mullite, as indicated by the presence of more lumps. These lumps were found to spread on the surface and become separated from each other in relatively large distance in the sample treated at $1250{ }^{\circ} \mathrm{C}$. In this case, the surface is marked by less uniform appearance and relatively coarse due to re-crystallisation during the heat-treatment; however, small grains of crystalline phases are also observed (Fig. 3d). In the sample treated at $1350{ }^{\circ} \mathrm{C}$, it can be observed that the lumps have agglomerated, marked by obvious grain boundaries between the agglomerates. With the aid of Rietveld analysis, it was found that the quantity of mullite increased from 30.9 to $67.7 \%$ as the temperature increased from 1150 to $1350^{\circ} \mathrm{C}$.

\section{Conclusions}

Sol-gel synthesis of mullite precursor has been successfully performed through the use of aluminum nitrate hydrate $\left[\left(\mathrm{Al}\left(\mathrm{NO}_{3}\right)_{3} \cdot 9 \mathrm{H}_{2} \mathrm{O}\right]\right.$ solution and silica sol extracted from rice husk. The FTIR analyses revealed the presence of Si-O-Si, Al-O-Al, and Si-O-Al functional groups, which is in accordance with the chemical structure of mullite. It was found that mullite formation started at $1150{ }^{\circ} \mathrm{C}$ and its abundance increased rapidly from 30.9 to $67.7 \mathrm{wt} \%$ as the temperature increased from 1150 to $1350{ }^{\circ} \mathrm{C}$. The existence of both fine and coarse grains of mullite was revealed by microstructure analysis.

\section{Acknowledgements}

The authorsare grateful to the Directorate General of Higher Education Republic of Indonesia for research funding provided through the Competency Research Grant, No.133/SP2H/PL/Dit. Litabmas/III/2012.

\section{References}


[1] W.K. Kriven, J.F. Siah, M. Schmucker, H. Schneider, High Temperature Microhardness of Single Crystal Mullite, J. Am. Ceram. Soc. 87 (5) (2004) 970-972

[2] H. Schneider, H. Okada, J.A. Pask, Mullite and Mullite Ceramics, Wiley Chichester-U.K, 1, 1994.

[3] A.P. Hynes, and R.H. Doremus, High Temperature Compressive Creep of Polycrystalline Mullite, J. Am. Ceram. Soc. 74 (10) (1991) 2469-2475.

[4] H. Schneider, and E. Eberhard, Thermal Expansion of Mullite, J. Am. Ceram. Soc. 73 (7) (1990) 2073-2076.

[5] R.R. Tumalla, Development of High Performance Interfill Material for System Chip Technology, J. Am. Ceram. Soc. 74 (2) (1991) 895-899.

[6] P. Pialy, N. Tessier-Doyen, D. Njopwono, and J.P Bonnet, Effects of Densification and Mullitisation on the Evolution of the Elastic Properties of a Clay Based Material during Firing, J. Eur. Ceram. Soc. 29 (9) (2009) 1579-1589.

[7] R. Barnwal, M.P. Villar, and R. Garcia, Flame Spray Pyrolysis of Precursor as a Route to Nano-Mullite Powder: Powder Characterization and Sintering Behavior, J. Am. Ceram. Soc. 84 (5) (2001) 951-956.

[8] I.A. Aksay, D.M. Dabbs, and M. Sarikaya, Crystallization Behavior of Cordierite-Based Glass with Excess $\mathrm{SiO}_{2}$ and $\mathrm{Al}_{2} \mathrm{O}_{3}$ at Initial Stage, J. Am. Ceram. Soc. 74 (2) (1991) 23432348.

[9] A.K. Chakravorthy, and D.K. Ghosh, Kaolinite-Mullite Reaction Series: The Development andSignificance of a Binary Aluminosilicate Phase, J. Am. Ceram. Soc. 74 (2) (1991) 23592364.

[10] I.M. Low and R. McPherson, The composition and structure of the Al-Si spinel, J. Mater. Sci. Lett. 7 (1988) 1196-1198.

[11] I.M. Low and R. McPherson, The origins of mullite formation, J. Mater. Sci. 24 (1989) 926-936. 
[12] I.M. Low and R. McPherson, Crystallization of gels in the $\mathrm{SiO}_{2}-\mathrm{Al}_{2} \mathrm{O}_{3}-\mathrm{ZrO}_{2}$ systems, J. Mater. Sci. 24 (1989) 1648-1652.

[13] H.S. Hong, and G.I. Messing, Anisotropic Grain Growth in Diphasic-Gel Derived TitaniaDoped Mullite, J. Am. Ceram. Soc. 81 (5) (1998) 1269-1277.

[14] D.R. Treadwell., D.M. Dabs, and I.A. Aksay, Mullite $\left(3 \mathrm{Al}_{2} \mathrm{O}_{3} \cdot 2 \mathrm{SiO}_{2}\right)$ Synthesis with Aluminoxiloxnes, Chem. Mater. 8 (80 (1996) 2056-2060.

[15] J. Aguilar-Santilan, H. Balmori-Ramirez, and R.C. Bradt, Dense Mullite from Attrition Milled Kyanite and $\alpha$-Alumina, J. Ceram. Process. Res. 8 (1) (2007) 1-11.

[16] J. Roy, N. Bandyopadhyay, S. Das, and S. Maitra, Studies on The Formation of Mullite from Diphasic $\mathrm{Al}_{2} \mathrm{O}_{3}-\mathrm{SiO}_{2}$ gel by Fourier Transform Infrared Spectroscopy, Iran Chem. and Chem. Eng. 30 (1) (2011) 65-71.

[17] L.S. Cividanes, T.M.B. Campos, L.A. Rodrigues, D.D. Brunelli, and G.P. Thim, Review of Mullite Synthesis Routes by Sol-Gel Method, J. Sol Gel Sci. and Tech. 55 (1) (2010) 111-125.

[18] C. Gerardin, S. Sundaresan, J. Benziger, and A. Navrotsky, Structural Investigation and Energetic of Mullite Formation from Sol-Gel Precursors, Chem. Mater. 6 (4) (1994) 160-168.

[19] C.Y. Chen, M.C. Wang, and M.H. Hon, Transformation Kinetics for Mullite in Kaolin Ceramics, J. Mater. Res. 118 (6) (2004) 1355-1362.

[20] C.Y. Chen, M.C. Wang, and M.H. Hon, Phase Transformation and Growth of Mullite in Kaolin Ceramics, J. Eur. Ceram. Soc. 24 (8) (2004) 2389-2397.

[21] S.C. Vieira, A.S. Ramos, and M.T. Vieira, Mullitisation Kinetics from Silica-and AluminaRich Waste, Ceram. Int. 33 (1) (2007) 59-66.

[22] T.H. Liou, Preparation and Characterization of Nano-Structured Silica from Rice Husk, Mater. Sci. and. Eng. A 364 (1-2) (2004) 313-323.

[23] F. Adam, K. Kandasamy, and S. Balakrishnan, Iron Incorporated Catalyst from Rice Husk Ash, J. Colloid Interface Sci. 304 (10 (2006) 137-143. 
[24] S. Zhu, S. Ding, H. Xi, and R. Wang, Preparation and Characterization of SiC/Cordierite Composite Porous Ceramics, Ceram. Int.33 (1) (2007) 115-118.

[25] W. Simanjuntak and S. Sembiring, The use of Rietveld Method to study the Phase Composition of Cordierite $\left(\mathrm{Mg}_{2} \mathrm{Al}_{4} \mathrm{Si}_{5} \mathrm{O}_{18}\right)$ Ceramics Prepared from Rice Husk Silica, Makara J. Sci. 15 (1) (2011) 97-100.

[26] S.K. Singh, B.C. Mohanty, and S. Basu, Synthesis of SiC from Rice Husk in a Plasma Reactor, Bull. Mater. Sci.25 (6) (2002) 561-563.

[27] B. Karmakar, P. Kundu, S. Jana, and R.N. Dwiredi, Crystallization Kinetics and Mechanism of Low Expansion Magnesium-Alumina-Silicate Glass Ceramics by Dilatometry, J. Am. Ceram. Soc.85 (10) (2002) 2572-2574.

[28] M.K. Naskar, and M. Chatterjee, A Novel Process for the Synthesis of Lithium Aluminum Silicate Powders from Rice Husk Ash and Other Water Based Precursor Materials, Mater. Lett. 59 (8-9) (2005) 998-1003.

[29] S. Sembiring, Synthesis and Characterization of Rice Husk Silica Based Borosilicate $\left(\mathrm{B}_{2} \mathrm{SiO}_{4}\right)$ Ceramics by Sol-Gel Routes, Indo. J. Chem. 11 (1) (2011) 85-89.

[30] T. Li, and T. Wang, Preparation of Silica Aerogel from Rice Hull ash by Drying at Atmospheric Pressure, Mater. Chem. Phys.112 (2) (2008) 398-401.

[31] J.P. Nayak, and J. Bera, Effect of Sintering on Phase-Formation and Mechanical Properties of Silica Ceramics Prepared from Rice Husk ash, Phase Trans. 82 (12) (2009) 879-888.

[32] S. Sembiring and W. Simanjuntak, X-ray Diffraction Phase Analyses of Mullite Derived from Rice Husk Silica, Makara J. Sci. 16 (2) (2012) 77-82.

[33] JADE Program XRD Pattern Processing PC, Material Data Inc (MDI), Livermore, CA (1997).

[34] B.A. Hunter, Software Rietica for 95/98 Window NT. Version 1.70, (1997).

[35] I. Ginting Suka, W. Simanjuntak, and K.D. Pandiangan, Potential Utilisation of Rice Husk Silica as Alternative For Mineral-derived Silica, Proceedings of International Seminar on 
Biomass Production and Utilization Challenges and Opportunities, Lampung of University, 396-402 (2009).

[36] F. Adam, and J.H. Chua, The Adsorption of Palmytic Acid on Rice Husk Ash Chemically Modified with Al (III) Ion Using the Sol-gel Technique, J. Colloid Interface Sci. 280 (1) (2004) 55-61.

[37] B.L. Orefice, and W.L. Vasconcelos, Sol-Gel Transition and Structural Evolution on Multicomponent Gels Derived from the Alumina-Silica System, J. Sol Gel Sci. and Tech.9 (9) (1997) 239-249.

[38] Powder Diffraction File (Type PDF-2). Diffraction Data for XRD Identification. International Centre for Diffraction Data, PA, USA, (1997).

[39] M.D. Sacks., K. Wang., G.W. Scheiffele, and N. Bozkurt, Effect of Composition on Mullitisation Behavior of $\alpha$-alumina/silica Micro Composite Powder, J. Am. Ceram. Soc. 80 (3) (1997) 663-672. 
Table. 1. Weight percentage (wt\%) from refinement of XRD data for the samples sintered at different temperatures for 6 hours. Estimated errors for the least significant digits are given in parentheses. [M: mullite, C: crystobalite, A: alumina, Q: quartz, PC: potassium Chlorate]

\begin{tabular}{rrrcrr}
\hline Temp $\left({ }^{\circ} \mathrm{C}\right)$ & $\mathrm{M}$ & $\mathrm{C}$ & $\mathrm{A}$ & $\mathrm{Q}$ & $\mathrm{PC}$ \\
\hline 950 & $1.1[2]$ & $17.9[5]$ & $0.3[1]$ & $43.3[1]$ & $37.4[8]$ \\
1150 & $30.9[1]$ & $20.1[5]$ & - & $15.1[1]$ & $28.7[4]$ \\
1250 & $43.8[1]$ & $28.6[4]$ & $1.7[1]$ & $12.1[5]$ & $13.9[2]$ \\
1350 & $67.7[4]$ & $27.8[2]$ & - & - & $4.5[3]$ \\
\hline
\end{tabular}


Table. 2. Figure-of merits (FOMS) from refinement of XRD Data for the samples sintered at different temperatures for 6 hours.

\begin{tabular}{lcccc}
\hline Temp $\left({ }^{\circ} \mathrm{C}\right)$ & $\mathrm{R}_{\exp }$ & $\mathrm{R}_{\mathrm{wp}}$ & $\mathrm{Rp}$ & $\mathrm{GoF}$ \\
\hline 950 & 12.36 & 16.34 & 12.76 & 1.74 \\
1150 & 12.96 & 19.02 & 14.41 & 2.14 \\
1250 & 13.06 & 19.27 & 14.79 & 2.17 \\
1350 & 13.16 & 17.87 & 13.56 & 1.84 \\
\hline
\end{tabular}




\section{Figure Captions}

1. FTIR spectra of non sintered sample (a) and the samples sintered at different temperatures, (b) $800{ }^{\circ} \mathrm{C}$, (c) $950{ }^{\circ} \mathrm{C}$, (d) $1050{ }^{\circ} \mathrm{C}$, (e) $1150{ }^{\circ} \mathrm{C}$, (f) $1250{ }^{\circ} \mathrm{C}$ and (g) $1350{ }^{\circ} \mathrm{C}$

2. The x-ray diffraction patterns of samples sintered at different temperatures,(a) $950^{\circ} \mathrm{C}$, (b) $1150^{\circ} \mathrm{C}$, (c) $1250^{\circ} \mathrm{C}$ and (d) $1350^{\circ} \mathrm{C} \cdot \mathrm{M}=$ Mullite, $\mathrm{Q}=$ Quartz, $\mathrm{A}=$ Corundum, $\mathrm{C}=$ Cristobalite.

3. SEM micrographs of samples sintered at different temperatures, (a) $950^{\circ} \mathrm{C}$, (b) $1050^{\circ} \mathrm{C}$, (c) $1150^{\circ} \mathrm{C}$, (d) $1250^{\circ} \mathrm{C}$ and (e) $1350^{\circ} \mathrm{C}$. Accelerating voltage $=20 \mathrm{kV}$, working distance $=11 \mathrm{~mm}$.

\section{Table Captions}

1. Weight percentage (wt\%) from refinement of XRD data for the samples sintered at different temperatures for 6 hours. Estimated errors for the least significant digits are given in parentheses. [M: mullite, C: crystobalite, A: alumina, Q: quartz, PC: potassium Chlorite]

2. Figure-of merits (FOMS) from Rietveld refinement of XRD data for samples sintered at different temperatures for 6 hours. 